\title{
Representações Sociais sobre as Drogas: um Estudo com Adolescentes em Conflito com a Lei
}

\author{
Samkya Fernandes de Oliveira Andrade \\ Faculdade Maurício de Nassau, PB, Brasil. \\ Railda Sabino Fernandes Alves \\ Universidade Estadual da Paraíba, PB, Brasil. \\ Maíne Helen Pereira de Almeida Bassani \\ Universidade Federal da Paraíba, PB, Brasil.
}

\begin{abstract}
Resumo: Sob a ótica da Teoria das Representações Sociais objetivou-se analisar as representações sociais acerca do uso de drogas entre os adolescentes em conflito com a lei e a existência da relação com o ato infracional. Trata-se de uma pesquisa com metodologia qualitativa com uma amostra constituída por 25 adolescentes em conflito com a lei, em cumprimento de medida socioeducativa de internação, na cidade de João Pessoa (PB). Como instrumentos foram utilizados: um questionário sociodemográfico e o desenho-estória com tema. Os dados foram analisados com o auxilio da Análise de Conteúdo Temática, proposta por Bardin. Os resultados mostram que $60 \%$ dos adolescentes pesquisados possuem idade entre 15 e 16 anos, com média de 16,3 anos ( $\mathrm{DP}=0,74)$. No que se refere ao ato infracional foi observado um número significativo de assalto (44\%), juntamente com tentativa de homicídio e latrocínio (48\%). A droga foi representada negativamente, como sendo responsável por trazer consequências relacionadas a problemas de saúde e a conflitos familiares. O crack foi citado como a droga mais destruidora e vinculada aos atos delitivos para manutenção do vício. Espera-se que os resultados encontrados possam contribuir para ampliar os conhecimentos existentes sobre a temática estudada e estimular reflexões sobre a promoção de práticas interventivas e preventivas junto aos adolescentes em medida socioeducativa.
\end{abstract}

Palavras-chave: Adolescente em Conflito com a Lei, Representação Social, Droga.

\section{Social Representations on Drugs: A Study with Adolescents in Conflict with the Law}

\begin{abstract}
The objective was to analyze the representations of adolescents in conflict with the law from the point of view of the Theory of Social Representations. This is a qualitative research with a sample of 25 adolescents in conflict with the law, in compliance with social educational internment measures, in the city of João Pessoa, Paraíba. A social demographic questionnaire and the "Drawings-Story with a Theme" tool were used as instruments. Data were analyzed with the aid of the Thematic Content Analysis proposed by Bardin. The results show that $60 \%$ of the adolescents surveyed were aged between 15 and 16 years, with an average of 16.3 years ( $\mathrm{DP}=0.74)$. Regarding the offense, a significant number of assaults (44\%), as well as attempted murders, and robberies followed by murder ( $48 \%)$ were observed. Drugs were negatively represented as being responsible for bringing consequences related to health problems and family conflicts. Crack was cited as the most destructive drug and was linked to criminal acts that maintain addiction. We hope that the results found may contribute to broaden the existing knowledge on the subject studied and to stimulate reflections to promote intervention and preventive practices among adolescents undergoing social and educational corrections.
\end{abstract}

Keywords: Adolescents in Conflict with the Law, Social Representation, Drugs. 


\title{
Representaciones Sociales sobre las Drogas: un Estudio con Adolescentes en Conflicto con la Ley
}

\begin{abstract}
Resumen: Bajo la óptica de la Teoría de las Representaciones Sociales se objetivó analizar las representaciones sociales acerca del uso de drogas entre los adolescentes en conflicto con la ley y la existencia de la relación con el acto infractor. Se trata de una investigación con metodología cualitativa con una muestra constituida por 25 adolescentes en conflicto con la ley, en cumplimiento de medida socioeducativa de internación, en la ciudad de João Pessoa - PB. Como instrumentos fueron utilizados: un cuestionario sociodemográfico y el Dibujo-Historia con tema. Los datos fueron analizados con el auxilio del Análisis de Contenido Temático, propuesto por Bardin. Los resultados muestran que el $60 \%$ de los adolescentes encuestados tienen edad entre 15 y 16 años, con una media de 16, 3 años ( $D P=0,74)$.En lo que se refiere al acto infractor se observó un número significativo de asalto (44\%), junto con intento de homicidio y latrocinio (48\%). La droga fue representada negativamente, siendo responsable de traer consecuencias relacionadas con problemas de salud y conflictos familiares. El crack fue citado como la droga más destructora y vinculada a los actos delictivos para mantener el vicio. Se espera que los resultados encontrados puedan contribuir a ampliar los conocimientos existentes sobre la temática estudiada y estimular reflexiones sobre la promoción de prácticas de intervención y preventivas junto a los adolescentes en medida socioeducativa.
\end{abstract}

Palabras clave: Adolescente en Conflicto con la Ley, Representación Social, Droga.

Diante das inúmeras acepções sobre drogas será utilizada, neste trabalho, a definição da Organização Mundial de Saúde (OMS) que conceitua droga como qualquer substância psicoativa, natural ou sintética, lícita ou ilícita, que possui algum princípio ativo capaz de alterar ou modificar o estado psíquico e orgânico daquele que faz uso dela (Galduróz, Noto, \& Carlini, 1997).

O uso de drogas é um fenômeno que tem aparecido em todas as épocas e sociedades, embora seu conteúdo e sua forma variem e evoluam constantemente, de acordo com as mudanças culturais e sociais. Assim, a droga, tal como outros elementos sociais, também acompanha a evolução das culturas e das sociedades (Maciel, \& Roque, 2016).

No percurso da humanidade, as drogas foram sendo percebidas de forma variada de acordo com a época ou com a cultura em que são consumidas. Por esse motivo, o seu estudo tem sido concebido a partir da compreensão de que a droga é um fenômeno social envolto em um contexto sociocultural, que revela que ela nem sempre foi vista como danosa e causadora de problemas. Suas representações podem estar relacionadas desde o contato com divindades, fontes de prazer e alívio de dores, até novas representações sociais de caráter mais negativo. Esta nova configuração representacional negativa foi inserida à medida que a droga e o seu uso deixaram de estar em determinadas culturas e contextos sociais e passam a romper as fronteiras, adquirindo novos contornos sociais e novas roupagens, com novas drogas sintéticas, com efeitos potencializados.

O fenômeno da droga tem sido alvo de interesse no campo científico e em diversos setores da sociedade, seja como reforçador de políticas proibicionistas ou por sua legalização. O certo é que o olhar sobre tal fenômeno deve reconhecê-lo como multideterminado por diversos componentes: biológicos, psicológicos, sociais e culturais. Hoje, alerta Nonticuri (2010), tem-se no Brasil, assim como em outros países, um grande número de drogas incluindo as consideradas ilícitas e aqueles que fazem uso destas são associados diretamente ao ato criminoso, sendo excluídos da sociedade.

A respeito desta vinculação entre droga, criminalidade e exclusão social, é possível constatar múltiplos discursos que perpassam a problemática do adolescente em conflito com a lei, especialmente nos meios de comunicação com matérias sensacionalistas sobre o quão "perigoso" é o adolescente que comete infração ou o quão insustentável é andar nas ruas sem ser impelido por um 
deles. No entanto, pouco se faz em termos de cuidado ou propostas interventivas, pois, se o lugar de exclusão é tomado pelo usuário de droga, ainda mais é aquele que, somado ao uso de drogas, comete infração (Melo, 2013).

Longe de querer estabelecer uma relação causal entre ambos os fenômenos, o que se objetivou na presente pesquisa foi conhecer e analisar as representações sociais acerca do uso de drogas entre os adolescentes em conflito com a lei e a existência da relação com o ato infracional, de forma a dar voz a esses adolescentes como um caminho para assinalar questões importantes para as políticas públicas que atuam e intervêm neste processo.

A amostra é específica, pois trabalha com uma parcela dos adolescentes, aqueles que cometem ato infracional e que estão em medida socioeducativa em regime de reclusão. De forma que vale a pena lançar um olhar reflexivo para a política de intervenção do Estado sobre a internação do adolescente, a qual remonta ao ano de 1942 quando foi criado o Serviço de Assistência ao Menor (SAM). Tal política adotou o modelo repressivo como forma de extinção da "criminalidade" com a criação dos reformatórios para abrigar os "menores delinquentes", com estrutura semelhante ao sistema penitenciário (Cruz, Hillesheim, \& Guareschi, 2005).

Em 1964, com o Golpe Militar, o SAM foi extinto e criou-se a Fundação Nacional do Bem-Estar do Menor (Funabem), que incluía atendimento aos carentes abandonados e aos infratores; e no âmbito estadual foram criadas as Fundações Estaduais de Bem-Estar do Menor (Febem), responsáveis pela execução das diretrizes elaboradas pela Funabem. Contudo, ainda havia o predomínio de uma ação corretiva sobre o adolescente em conflito com a lei, pois se acreditava que só assim seriam possíveis a reeducação e a reintegração do adolescente à sociedade (Cruz et al., 2005; Espíndula, \& Santos, 2004). Mas, estas instituições longe de adotar uma política efetivamente inclusiva, fomentava a exclusão sociofamiliar, conforme afirma Bulcão (2001):

A internação nestes estabelecimentos, mais que a educação e recuperação dos menores, privava-os da liberdade, afastando-os do convívio das ruas, encaradas como espaço pernicioso [...]. Outra preocupação que se fazia presente naquela época, e que se verifica até os dias de hoje, era a tendência de se oferecer ofícios profissionalizantes em oficinas, que preparam para o trabalho, mas em funções socialmente desvalorizadas e de baixa remuneração (p. 60).
Em 1980 houve nova mudança impulsionada por uma crescente mobilização social contra a ditadura e a favor de um Estado democrático, o que resultou na redemocratização política da sociedade brasileira e representou a consolidação do cenário de luta pelos direitos políticos, civis e sociais, como a reconquista ao direito de expressão individual e coletiva e o voto popular, com as reivindicações das eleições diretas para presidente da república, pelo Movimento das Diretas Já entre 1984 e 1985 (Perez, \& Passone, 2010). Este novo panorama de luta pelos direitos revelou a urgência de políticas sociais de atendimento à criança e ao adolescente; culminando na elaboração da Constituição de 1988 e de outras ordenações legais de cunho social, como o Estatuto da Criança e do Adolescente (ECA), Lei Federal no 8.069, aprovado em 13 de julho de 1990, o qual veio a substituir o Código de Menores tendo como objetivo garantir a proteção integral para todas as crianças e adolescentes brasileiros até os 18 anos de idade (Espíndula, \& Santos, 2004; Conselho Federal de Psicologia, 2010).

Dentre os avanços presentes no ECA destaca-se o entendimento de que a criança e o adolescente são sujeitos de direitos e deveres, e que não são meros objetos passivos, passando-se a considerar sua condição de pessoa em desenvolvimento e a abolição das nomenclaturas como "menor", "infrator", "abandonado", tendo em vista a conotação pejorativa e preconceituosa que tais termos carregam (Bastos, 2002; Castro, 2002). Com o ECA, estabeleceu-se, ainda, a abertura para a participação popular nas políticas de assistência, através da criação dos Conselhos municipais, estaduais e nacional. O que, de acordo com Cruz et al. (2005) iniciou uma nova fase de desinstitucionalização e descentralização, que permitiu a participação da sociedade na elaboração e no controle de políticas para a infância.

O ECA é o documento legal de regulamentação dos direitos referentes aos adolescentes em conflito com a lei; nele são esclarecidas as nomenclaturas específicas que envolvem esse público, e são diferenciados os termos "ato infracional" e "crime". O ato infracional é definido como a transgressão das normas estabelecidas, do dever jurídico, praticado por um adolescente entre 12 e 18 anos (considerando a idade na data do fato). Sobre o "crime", o ECA alerta que para crianças e adolescentes não se pode usar criminalização em casos de menores de 18 anos; não cabe a responsabilização penal, mas a aplicação de medidas socioeducativas, que são: advertência, obrigação de reparar o dano, 
prestação de serviços à comunidade, liberdade assistida, inserção em regime de semiliberdade e/ou internação em estabelecimento educacional. A aplicação de tais medidas levará em conta a capacidade do adolescente em cumpri-la e a gravidade da infração (Lei No 8.609, 1990; Francischini, \& Campos, 2005). Apesar disso, na presente pesquisa, optou-se pelo o uso da terminologia "crime", por ter sido constatado no estudo piloto que este termo está mais próximo da realidade dos adolescentes do que "ato infracional".

$\mathrm{O}$ presente estudo diz respeito aos adolescentes que cumprem medidas de internação. Tal medida, apresentada no artigo 121 do Estatuto, define a internação como uma medida privativa de liberdade, sendo aplicada quando o adolescente é pego em flagrante $\mathrm{e}$ por ordem estrita do juiz. A manutenção da medida deve ser reavaliada a cada seis meses, sem exceder o prazo máximo de três anos. Após isso, o adolescente deverá ser liberado e colocado no regime de semiliberdade ou liberdade assistida (Lei No 8.609, 1990).

Para estudar as drogas e suas representações numa perspectiva que privilegia o aspecto social, cultural e histórico fez-se uso do aporte teórico das Representações Sociais (RS) desenvolvida por Moscovici, a partir de investigações acerca da crescente propagação da psicanálise entre a população francesa na década de 1950. Os achados de Moscovici são reunidos na publicação intitulada La psychanalyse: son image et son public (1961), dedicada a estudar o processo de transformação de uma teoria científica, no caso, a psicanalítica, em um saber do senso comum, objetivando conhecer a construção do cotidiano e os processos responsáveis pela mudança de pensamento e das práticas sociais (Almeida, Santos, \& Trindade, 2011; Sá, 1998; Vala, 1993). Sendo assim, Moscovici (2003), entende representação social como um:

Sistema de valores, de noções e práticas tendo uma tendência: antes de tudo, instaurar uma ordem que permite aos indivíduos a possibilidade de se orientar no meio-ambiente, social, material e de o dominar. Em seguida; de assegurar a comunicação entre os membros de uma comunidade propondo-lhes um código para nomear e classificar de maneira unívoca as partes do seu mundo, de sua história individual ou coletiva (p. 31).

A Teoria das Representações Sociais (TRS) sustenta que a incorporação do novo e do não familiar ao uni- verso consensual do sujeito está na base da formação das representações sociais e constitui-se um dos aspectos centrais da TRS. Trata-se de processos cognitivos regulados por fatores sociais entendidos como objetivação e ancoragem. Proposta por Moscovici, a ancoragem é um processo pelo qual se procura incorporar o estranho e não familiar ao sistema de pensamento já existente e a objetivação diz respeito ao processo mediante o qual o invisível se torna perceptível, ou seja, o de tornar concreto o que é abstrato (Alves, 2001; Reis, \& Bellini, 2011).

O desenvolvimento da TRS levou à sua ampliação e à consequente inauguração de outras correntes complementares. Assim, para distinguir as proposições básicas de Moscovici das outras perspectivas advindas dos colaboradores posteriores a ele, foi estabelecido o termo "grande teoria". É a partir da grande teoria que se desdobram as principais perspectivas: a societal, dimensional, estrutural (Alves, 2001; Almeida, 2009). $\mathrm{O}$ presente utilizou a abordagem dimensional em que o enfoque tem como pressuposto a compreensão do saber do senso comum, com vistas à tentativa de construção e interpretação das representações e práticas construídas pelos sujeitos (Jodelet, 2001).

Acerca da perspectiva dimensional Moscovici (1978) afirma que a RS de determinado objeto existe apenas se este tiver um significado social nas conversações cotidianas - como é o caso da droga entre os adolescentes em conflito com a lei - pois, mesmo aqueles que não fazem ou nunca fizeram uso de droga, geralmente, estão envoltos em um contexto onde a droga está presente, fazendo com que elaborem e criem uma representação acerca de tal objeto social. Nesse aspecto também vale destacar que as RS são influenciadas pelas condições sócio-históricas que as originaram, o que leva a serem explicadas e entendidas de acordo com as condições sociais dos grupos que lhe deram origem e, por esse motivo, ressalta-se a importância da descrição dos grupos sociais estudados.

Assim, a abordagem dimensional auxiliou a compreensão e a construção dos processos dimensionais constituintes do uso da droga para o grupo social estudado - os adolescentes em conflito com a lei; apreendendo assim o senso comum que os permeia e significa.

\section{Método}

Trata-se de uma pesquisa exploratória, de campo e descritiva, com metodologia qualitativa como principal referência. A qual é definida por Minayo e Sanches (1993) como a metodologia que procura "enfocar, 
principalmente, o social como um mundo de significados passível de investigação e a linguagem comum, ou a fala, como a matéria-prima desta abordagem, a ser contrastada com a prática dos sujeitos sociais" (p. 239).

A amostra não probabilística, por conveniência, foi constituída por 25 adolescentes em conflito com a lei, do sexo masculino, em cumprimento de medida socioeducativa de internação no Centro Educacional do Adolescente (CEA), localizado na cidade de João Pessoa (PB). Os participantes foram definidos pelo o uso do critério de saturação, que estabelece a suspensão dos dados, quando estes, na avaliação do pesquisador, não mais oferecerem novas categorias ou representações, apresentando redundância ou repetição (Fontanella, Ricas \& Turato, 2008).

Como critério de inclusão, consideraram-se os adolescentes institucionalizados em cumprimento de medida socioeducativa de internação, respeitando o critério de aceitabilidade e disponibilidade dos mesmos. Como critério de exclusão, aqueles que apresentassem qualquer comprometimento cognitivo que interferisse na compreensão dos instrumentos e os que não aceitassem participar da pesquisa.

Os instrumentos de coleta de dados foram: um questionário sociodemográfico e o desenho-estória com tema. O questionário teve por objetivo recolher informações relativas ao perfil sociodemográfico. O desenho-estória com tema é uma técnica que advém da psicologia clínica, tendo sido adaptada para o campo da pesquisa em psicologia social e aos estudos da RS na década de 1980 . No campo da pesquisa, o desenho-estória objetiva apreender, por meio da projeção temática e gráfica, elementos latentes, essenciais para a compreensão dos significados (Coutinho, Serafim \& Araújo, 2011).

Como procedimento de aplicação da técnica foi apresentado o seguinte estímulo: "Desenhe um usuário de drogas", pedindo posteriormente: "Conte uma estória sobre este desenho".

Como procedimento de análise seguiu-se, por sugestão de Coutinho et al. (2011), os seguintes passos: observação sistemática dos desenhos; seleção dos desenhos por semelhança de temas; leitura flutuante das unidades temáticas das histórias; construção de categorias. Para construção das categorias foi utilizada a análise de conteúdo temática proposta por Bardin (2010).

A pesquisa respeitou todos os preceitos éticos integralmente previstos pela Resolução CNS n ${ }^{\circ}$ 466 / 12 do Conselho Nacional de Saúde. Só foi iniciada depois de obter toda a documentação necessária, principalmente a aprovação do Comitê de Ética (Parecer $\mathrm{n}^{\circ} 722.054 / 2014$ ) e a aprovação da instituição onde a pesquisa foi realizada.

A coleta de dados foi iniciada com o estabelecimento do rapport e com assinatura do Termo de Consentimento Livre e Esclarecido, e o fornecimento das informações sobre o objetivo da pesquisa e o caráter voluntário e sigiloso da participação.

No CEA a aplicação dos instrumentos foi feita nos dias estabelecidos pela instituição, partindo de uma lista fornecida pela mesma, com os nomes dos adolescentes que comporiam a amostra naquele dia. Objetivando a privacidade, os instrumentos foram aplicados em uma sala onde ficavam apenas o adolescente e a pesquisadora; ficando o agente de segurança do lado de fora da sala, mantendo contato visual, como condição de segurança posta pela instituição.

\section{Resultados e discussões}

\section{Dados sociodemográficos}

O perfil dos participantes demonstra que a idade da amostra variou entre 15 e 18 anos, sendo que $60 \%$ (n = 15) possuem idade entre 15 e 16 anos, com média de $16,3$ anos ( $\mathrm{DP}=0,74)$. Dado consoante com a pesquisa realizada em 2012 pelo Departamento de Pesquisas Judiciárias do Conselho Nacional de Justiça (CNJ), que traçou o perfil de 17.500 jovens que cumprem medidas socioeducativas no Brasil, dos quais 1.898 adolescentes em cumprimento de medida de privação de liberdade apresentam média de idade de 16,7 anos. Os dados de ambas as pesquisas também coincidem quanto ao uso de drogas ilícitas, onde na presente amostra $72 \%$ $(\mathrm{n}=18)$ dos adolescentes fazem ou já fizeram uso de alguma droga ilícita, sendo a maconha a mais utilizada (68\%, $\mathrm{n}=17$ ); dado coincidente em panorama nacional, onde $75 \%$ dos adolescentes apontam a maconha como a droga mais utilizada entre eles. Corroborando estudos que assinalam ser a maconha a droga ilícita mais usada no Brasil pelos adolescentes em conflito com a lei (Martins, \& Pillon, 2008).

A amostra apresenta um predomínio da baixa escolaridade, onde apenas um $(n=1)$ adolescente possuía Ensino Médio Incompleto, os demais possuíam apenas ensino fundamental completo $64 \%$ $(\mathrm{n}=16)$ e incompleto $56 \%(\mathrm{n}=14)$. Esse cenário tam- 
bém foi encontrado em outras pesquisas (Costa, Carvalho, Wentzel, 2009; Luz, Eduardo, Mota, \& Pinheito, 2005). Castro (2002) e Zhang, Willson, Katasiyannis, Barret, Ju e Wu (2010) afirmam que a baixa escolaridade é apontada na literatura como um fator de risco para a entrada do adolescente na prática do ato infracional. Panorama apreendido em 2002, em nível nacional, quando $51 \%$ dos adolescentes com medida socioeducativa de internação estavam sem estudar no momento da apreensão e $6 \%$ não eram alfabetizados. Em 2011, os números aumentaram para $57 \%$ e $8 \%$, respectivamente (Assis, \& Constantino, 2005; Conselho Nacional de Justiça, 2012). Costa (2005) criticando o sistema de medidas socioeducativas, afirma que apesar de que atos infracionais ocorram em todas as classes sociais, o que se vê, de fato, é a perpetuação de um cenário onde a prática de atos infracionais anda junto com a pobreza e o baixo nível de escolaridade.

Bazon, Silva e Ferrari (2013) apontam que os aspectos da vivência escolar que estão diretamente associados à conduta infracional incluem: baixo desempenho, que influencia no enfraquecimento do vínculo escolar, mediante o sentimento de incompetência e exclusão; e relação conflituosa com colegas e professores, que pode estar associada ao comportamento problemático do aluno, levando-o, por sua vez, a contínuas punições e, consequentemente, ao enfraquecimento do vínculo com a escola.

No que se refere aos atos infracionais, na presente pesquisa, observa-se a prevalência de assalto (44\%) seguido de homicídio (48\%) como ato infracional responsável pela internação dos adolescentes, fenômeno também observado na pesquisa do CNJ (2012) que apontou a prevalência de assalto em todas as regiões do Brasil (47\% na região Nordeste). Acerca dos tipos de atos infracionais, Coimbra e Nascimento (2005) asseveram que a entrada dos adolescentes nesse universo pode estar associada ao fato de que os mesmos, geralmente advindos da camada pobre da sociedade, enfrentam dificuldade de acesso ao mercado de trabalho formal. Assim, a atuação em redes ilegais de narcotráfico e outras práticas infracionais, como o assalto, por exemplo, parecem ser a única forma de sobrevivência.

\section{Desenho estória com tema}

Seguem-se os dados referentes à análise do desenho-estória com tema, cujo corpus foi constituído por 25 desenhos e estórias temáticas, que, aqui, em função da limitação de espaço, seria impossível demonstrar tudo. Tais desenhos versaram sobre o tema único: usuário de drogas. $\mathrm{O}$ material obtido foi submetido à análise de conteúdo temática de acordo com as semelhanças no conteúdo das estórias e no grafismo; tendo surgido uma categoria maior denominada droga-crime, a qual foi agrupada em sub-categoria denominada de causas e consequências do uso das drogas. Esta categoria diz respeito aos conteúdos e grafismos relacionando diretamente aos fenômenos drogas e crime, visto que, o fenômeno da criminalidade, para os sujeitos do estudo, é algo significativo, que se faz presente a todo momento nos seus discursos e nas suas vidas, entrecortando suas representações e suas vivências. Os grafismos seguidos pelos conteúdos verbais serão demonstrados de modo intercalado com as discussões.

A categoria droga-crime reúne os desenhos, juntamente com suas estórias, que descrevem a existência da relação da prática do ato infracional com a droga, sendo o tipo de crime predominante na relação com a droga - o assalto, usado como fonte de obtenção de dinheiro para compra de droga; sendo o uso abusivo/ dependência associado como causa direta para a prática do ato infracional (crime); sendo a prática do ato infracional decorrente do vício incontrolável da droga.

Além disso, os desenhos-estórias também descrevem as causas do uso das drogas, desde o início, vinculando a representação da maconha, até a dependência da droga; apontando como principal causa do uso, a influência de amigos como exemplificado nos desenhos e estórias a seguir. Para ilustração foram escolhidas alguns desenhos e estórias mais representativas dos conteúdos aqui discutidos, os quais serão demonstrados no corpo do texto.

Verificou-se que a droga foi representada pelos adolescentes como devastadora, acarretando graves consequências à saúde, desde problemas orgânicos graves até problemas de memória que interferem na escola. Como atesta o discurso a seguir:

Estudar eu não digo que ele vai conseguir estudar que, como eu tava vendo na tela (televisão) ontem, ele vai ter... Ele vai conseguir estudar alguns anos, mas ele vai ter perca de memória.

Pessoa que usa droga fica magra, fica fraco, não tem agilidade para correr, cansa rápido.

Sobre a representação dos efeitos maléficos da droga, apesar de a maconha ter sido a droga ilícita 
de maior consumo entre a população investigada ( $\mathrm{n}=21 / 30,3 \%$ ), é o crack, com prevalência de consumo $\mathrm{n}=4(5,7 \%)$, que aparece como a droga de maior capacidade destruidora. Os adolescentes atribuíram o comportamento desviante e delinquente à necessidade de obtenção da droga, tal como descrito nos conteúdos semânticos das estórias. O uso de crack, foi considerado baixo na população entrevistada, sendo assim, as representações construídas sobre esta droga foram formadas pelo conhecimento socialmente elaborado e partilhado, que contribue para a construção de uma realidade comum a um conjunto social (Jodelet, 2001), perpassando os significados circulados nos meios de comunicação que, no caso das drogas, estão imbuídos do discurso de combate às drogas até chegar às representações elaboradas pelos adolescentes, havendo, nesse percurso, influência mútua de ambos os universos.

A figura 1 aponta a droga como tendo uma representação negativa, o que corrobora com estudos de Martins, Santo, Percílio e Kern (2006) ao afirmarem que, prioritariamente, a droga é tida como algo ruim

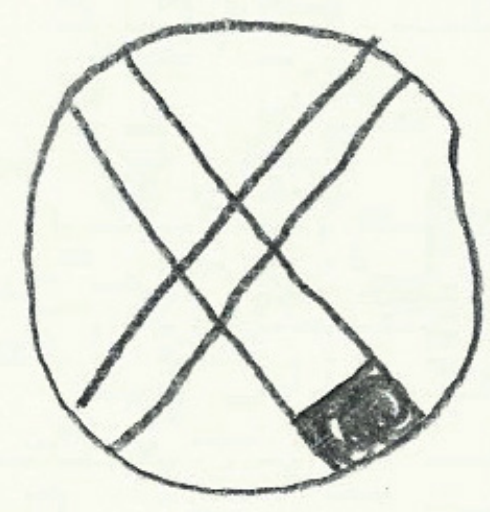

Proibido fumar. Drogas, cigarro, tudo isso faz mal à saúde. Crack também é uma droga que tá matando muita pessoa. Essa droga aí (crack)... muito ruim, já tive família que já usou isso aí. Acho essa droga aí muito ruim. Por causa dessa droga aí que meu pai e minha mãe se separou. Quando ele fumava (pai), começou logo a vender tudo. Que é que eu diria? (para alguém que começa a usar drogas) Não entre nessa não que... porque só tem dois caminhos, ou cadeia ou cemitério. Se quiser escutar, escute, se não quiser... Só tem esses dois caminhos. Se quiser escutar, escuta, se não quiser...

Figura 1

Categoria relação droga x crime.
No presente estudo, além dos problemas orgânicos, a droga também foi associada a problemas familiares e à morte, sobretudo em função do tráfico de drogas ou do próprio uso.

Se ficar usando só faz morrer mesmo, porque o crack mata! quando via os bicho usando só ficavam mais magro ainda, os caba fumando esses negócio de crack só ficava mais magro ainda, aí cada vez que ele vai ficando mais, ele vai morrendo né, vai emagrecendo, se ele não aguentar ele morre, então ou ele para ou morre.

Esta associação também foi encontrada no estudo de Melo (2013) com usuários de crack em tratamento. O que parece contraditório, pois, mesmo havendo a representação negativa da droga por parte dos adolescentes, tal representação não foi suficiente para evitar o uso ou experimentação, visto que $72 \%$ dos entrevistados fazem ou já fizeram uso de alguma droga ilícita. Isso ocorre, possivelmente, devido à crença de que a droga é poderosa, que torna o sujeito passivo, a ponto de deixá-lo totalmente impotente e sujeito a cometer crimes, como demonstrado na figura 2 , relacionando diretamente o uso de droga a prática de crimes,

A influência de amigos para o uso de drogas, por sua vez, pode ocorrer inicialmente pela pressão dos pares ou ainda pela necessidade de se sentir pertencente ao grupo, situações estas anteriores à necessidade propriamente dita do consumo da droga. De acordo com Pereira e Sudbrack (2008) a droga atua, nesse contexto, como facilitadora de vínculos e promove a formação de uma imagem e identidade grupal.

Má influência, começou a se envolver com as coisas erradas, com más amizades, começou a fumar. Vendo os amigos dele fumando, foi experimentar e ficou aviciado e fumou, ficou fumando.

Nas representações acerca das drogas, os sujeitos desta pesquisa afirmaram que as drogas, sobretudo o crack, exercem forte influência neles a ponto de mudarem a vida deles e os obrigarem a atos infracionais, assumindo, dessa forma, um papel de vítimas de amizades e de traficantes. Este aspecto da representação do usuário de drogas e das drogas remete à incapacidade atribuída ao usuário de lutar contra o seu estado de dependência, desacreditando na sua própria recuperação. 


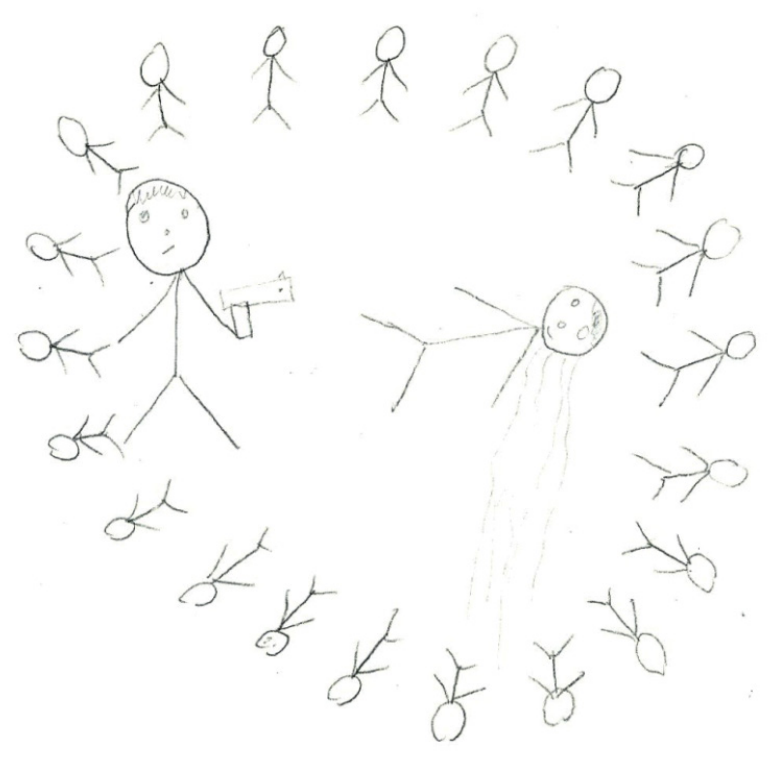

Isso aqui significa um homicídio que acabou de acontecer, isso aqui é o sangue e esses são os curiosos tudo olhando, as pessoas vendo o homem fazendo o homicídio. Matou por causa de droga, o que foi morto é usuário de drogas e o que matou era o traficante, o que morreu tava devendo a ele, a pessoa não consegue pagar o vício, ai dá nisso, mas graças a Deus que eu não uso droga, é só amizade só, conheço uns amigos que já morreu já, tenho amigo que morreu bem pertinho de mim já por causa de droga.

Figura 2

Categoria relação droga x crime.

É difícil sair desse vício. É difícil... vender televisão, negócio da mãe dele, cada vez mais ficando pior. Nunca ninguém se recupera disso não.

O cracké representado como a droga que faz mal, leva à morte, ao tráfico e ao roubo, vinculando o indivíduo à marginalidade, fazendo com que este fique atrelado à pecha de criminoso, e, portanto, sem valor na sociedade.

Dou valor a quem usa pedra não. Pra mim não presta não, porque pedra tem o que dá não. Pedra a pessoa fica noiada e fica devendo aí morre ligeiro demais homi. Perde tudo o que tem. Ninguém dá valor a quem fuma pedra não.

É um bad boy. Usa droga e quando não tem dinheiro para comprar vai roubar, aí termina vindo praqui.
Como visto nas estórias descritas, os adolescentes praticam o ato infracional para garantir a manutenção do uso da droga, destacando um quadro de dependência da droga e o roubo para manutenção do vício, mas se colocando como vítima dos traficantes.

Ela rouba, assalta para sustentar o vício [...] é viciada em maconha e crack.

Fumo, boca de fumo. Assaltando os carros por aí, fazendo o que não presta... assaltando para usar a droga.

Esse fenômeno corrobora o que Costa et al. (2009) discutem, ao afirmarem que o envolvimento com drogas se apresenta como um dos fatores de motivação para a prática do ato infracional, seja para compra ou venda. White, Jackson e Loeber (2009), também concordam ao afirmarem que o consumo de drogas acontece anteriormente ao ato infracional, apoiados por estudos longitudinais que comprovam que distúrbios comportamentais precedem o consumo de drogas, com a explicação de que a prática infracional estaria em consonância com a visão desviante de mundo (Fonseca, 2013).

Todavia, não há um consenso de como, de fato, ocorre tal relação; contudo, o que se propõe é a investigação associada aos diversos contextos de vulnerabilidade em que o adolescente está inserido. Considerando esta linha de raciocínio, o objetivo desta investigação não foi estabelecer uma relação causal entre drogas e ato infracional, mas compreender o problema do uso de drogas a partir das três dimensões propostas por Olievenstein (1985): o encontro de um produto, de uma personalidade e de um momento sociocultural, propícios ao exercício da infração. Fato este encontrado na presente pesquisa onde há uma confluência entre o consumo de drogas, o ato infracional e a vulnerabilidade social, como a baixa escolaridade e o baixo nível socioeconômico. Isto ressalta a discussão de que a atual medida de enfrentamento às drogas não se configura como a melhor medida, posto que o ato infracional é apenas uma ponta de um conjunto de fatores muito maior e mais complexo.

Partindo-se do entendimento destacado por Moscovici (2012) de que as representações sociais são entidades que circulam e se cristalizam através da fala e do contato com o universo cotidiano, a relação constantemente reforçada pela mídia acerca do uso de drogas e a prática criminosa, pode ser um dos fatores responsáveis para a construção, no meio social e con- 
sequentemente entre os adolescentes em conflito com a lei, desta relação de causa e efeito. Assim, reforça-se a lógica de que a pessoa que faz uso de drogas é o responsável pela violência no país e a ele se atribui o título de marginal, o que acaba por contribuir ainda mais para a exclusão social de tais indivíduos (Melo, 2013).

Para a compreensão do fenômeno do ato infracional, Souza e Resende (2016) advertem que o estudo acerca da prática do crime na adolescência deve ser investigado juntamente com outros comportamentos problemas, incluindo o uso de drogas, mas também o abandono da escola, envolvimento com gangues ou problemas familiares. Apesar de não ser estabelecida uma relação causal, devem-se levar em consideração os fatores associados à prática do ato infracional. No caso da presente pesquisa a relação causal foi estabelecida pelos próprios adolescentes, constituindo-se em uma representação construída a partir das experiências pessoais, no caso do próprio envolvimento do adolescente com o crime conjuntamente com a droga. Tal análise apresenta consonância com o pensamento de Moscovici (2012) quando descreve que as representações são elaboradas a partir de um objeto inscrito em um contexto parcialmente concebido pelo sujeito ou pelo grupo, dependendo, assim, da atitude e da experiência pessoal perante o objeto social. Dessa forma, assume-se que os adolescentes em conflito com a lei, na medida em que organizam e reconstroem a representação da droga em conjunto ao ato infracional, se situam no universo social.

Acerca da subcategoria consequências do uso de drogas, as estórias elaboradas pelos atores da pesquisa descrevem as consequências do uso de drogas como sendo a morte ou a cadeia.

$\mathrm{O}$ discurso apresentado na figura 3 repercute a máxima do senso comum de que a prática do mal, inevitavelmente será recompensada com o mal para quem o pratica. Outras consequências apontadas pelos adolescentes acerca do uso de droga, dizem respeito ao prejuízo que esta acomete a saúde, como demonstrado na figura 4, e o prejuízo na relação familiar. Os grafismos seguidos pelos conteúdos verbais demonstrados contemplam, predominantemente, elementos referentes ao que os adolescentes entrevistados entendem e atribuem às consequências do uso de drogas.

O prejuízo na relação familiar é descrito pelos adolescentes, representado pelo afastamento da família, como observado na estória e no desenho-estória, respectivamente:
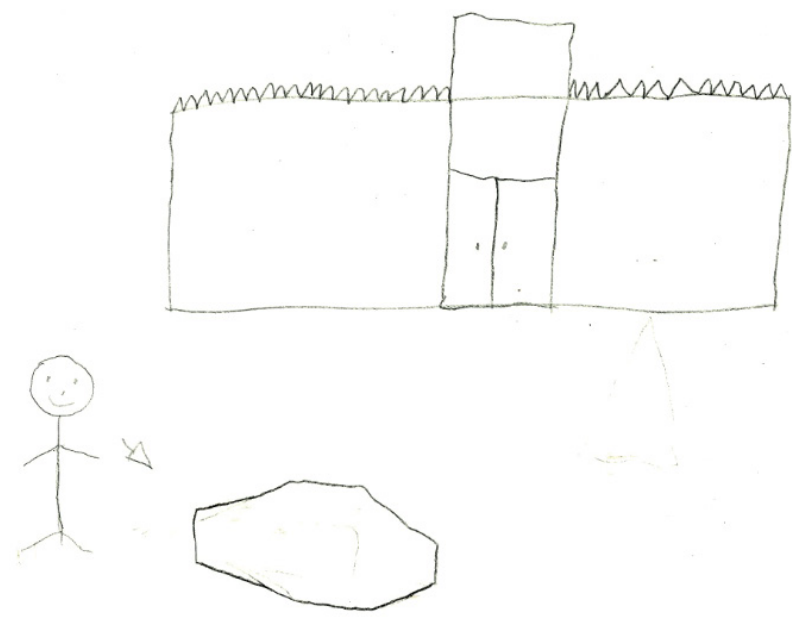

É quem usa droga. Andou com mau caminho, mau companhia dos amigos, os amigos influenciou a usar droga aí ele começou. Depois ele saiu e continuou nessa vida e só pode dá morte ou cadeia, se ele foi preso foi porque Deus deu um livramento pra ele, dele não morrer, mas se ele sair e continuar, é capaz de morrer, se continuar na mesma vida. já morreu já, tenho amigo que morreu bem pertinho de mim já por causa de droga.

Figura 3

Subcategoria Consequência do uso de drogas.

Ela já morou com a família, família pôs pra fora.

Dado também representado na pesquisa de Melo (2013), que constatou que a relação prejudicada no âmbito familiar decorre do abandono do investimento afetivo em tais relações. Assis e Souza (1999) constataram, em sua pesquisa a importância da família para o público adolescente em conflito com a lei, mesmo entre aqueles que não apresentam vínculos familiares preservados, pois a família é representada como fonte de apoio e suporte, reconhecidamente nesse momento de privação de liberdade.

A entrada no universo infracional e o cumprimento de medida socioeducativa de internação faz com que o adolescente se decepcione com o grupo e passe a construir uma imagem negativa dos pares, valorizando aqueles que permaneceram com ele. Assim, os desenhos-estórias evidenciaram as representações negativas acerca da droga e do ato infracional, corroborando os resultados até aqui apresentados, deixando os adolescentes mais livres na descrição da relação estabelecida entre a droga e o ato infracional, pois, apesar de estarem descrevendo uma estória, colocam nela suas vivências e experiências. Acerca da representação social Moscovici (2011) afirma que 


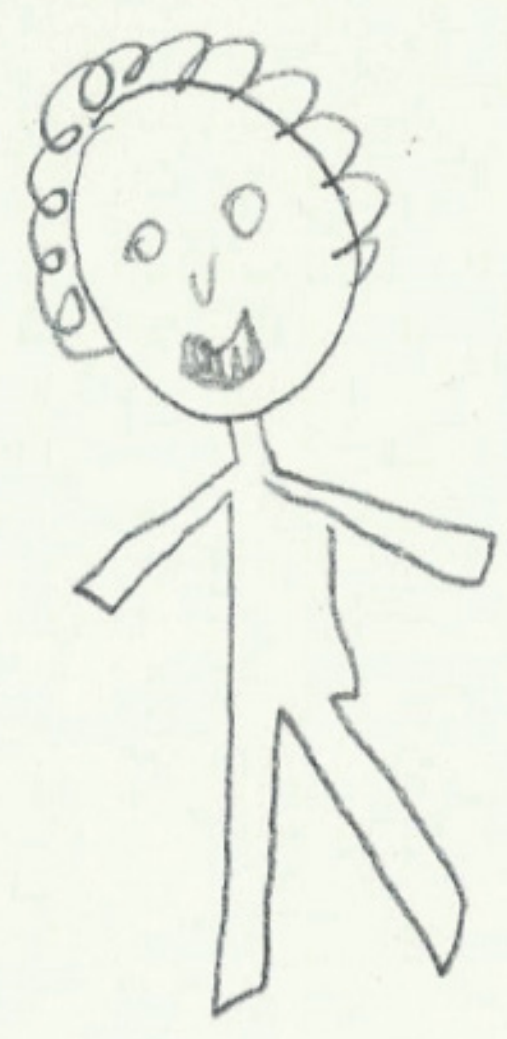

Destruído, é feio, acabado, pelo uso da droga e depende da droga, nesse caso aqui seria o crack. Três anos. Influência dos amigos. Gostou de usar e se afundou... Perde o lar, já vi gente fazer isso, perder mulher, filho, esposa, até às vezes até morrer. Porque tem viciado que compra e não paga né, o jeito é matar. Já vi gente, amigo meu parar de fumar maconha, crack, consegue só basta ele querer. Eu bebia e fumava. Hoje eu não faço mais isso, eu fumava aqui dentro, que o cigarro aqui é um passatempo.

Figura 4

Subcategoria Consequência do uso de drogas.

o sujeito ao representar algo é envolvido pelos valores presentes na sociedade da qual faz parte, ou seja, "ao mesmo tempo em que possuem uma contextura psicológica autônoma, as representações sociais também são próprias da sociedade e da cultura” (Melo, 2013, p. 113).

\section{Considerações finais}

O uso de drogas tem sido tomado como objeto de estudo no meio científico, devido ao entendimento de que tal fenômeno tem se tornado um problema de saúde pública, ao afetar não apenas aquele que faz uso da droga, mas todo o contexto em que este está inserido, como seus familiares e a comunidade da qual faz parte.
No caso do adolescente em conflito com a lei, agrega-se ao estigma de uso de drogas já comumente conhecido, o estigma da prática do crime. Aos adolescentes são atribuídas denominações pejorativas e diminuídas, tais como "marginalzinho", "bandido" e "delinquente". Taxonomia que os distanciam da população em geral e até da comunidade científica, dificultando ainda mais o entendimento de tal fenômeno.

A presente pesquisa objetivou conhecer e analisar as representações sociais acerca do uso de drogas entre os adolescentes em conflito com a lei e a existência da relação com o ato infracional, dando ainda voz a esses sujeitos que, por vezes, se encontram em situação de exclusão social, tendo suas demandas constantemente silenciadas.

Longe de querer pontuar culpados, não se pode deixar de mencionar que a falha se dá na inoperância da comunicação de toda a rede que compõe as políticas sociais e de assistência, nas áreas de saúde, educação, segurança, lazer, saneamento, cultura, entre outras, que poderiam atuar conjuntamente em ações preventivas e interventivas, evitando as práticas desviantes.

Destaca-se ainda, que o sensacionalismo da mídia, através de recorrentes matérias que envolvem o adolescente na prática de atos infracionais, relacionando-os diretamente às drogas, além de suscitarem discussões unilaterais e simplistas sobre a questão da redução da maioridade penal, legitima e torna natural a associação do adolescente em situação de vulnerabilidade social com as drogas e a infração. O que leva grande parte do público à alienação e ao incentivo de uma postura de combate, não apenas às drogas, mas, sobretudo, combate ao usuário.

Diante da complexidade do estudo acerca fenômeno da infração entre os adolescentes, o que parece ser consenso é que tal fenômeno ocorre entre personagens que perpassam geração após geração, inalcançados pelas políticas públicas de educação, saúde, cultura, lazer e profissionalização.

Diante das limitações da presente pesquisa, dentre elas, o número reduzido de participantes, que não permite a generalização dos resultados, entende-se que o objetivo de dar voz a esses sujeitos sociais foi alcançado. Voz que está totalmente ausente nos setores midiáticos e sociais, que longe de ser um ideal representativo, ao menos, tentou-se compreender suas vivências, suas práticas e representações, a fim de que a intervenção com tal população aconteça a partir de problemáticas por eles ressaltadas. 
Espera-se, assim que os resultados encontrados neste estudo possam contribuir para ampliar os conhecimentos existentes acerca do fenômeno da droga, juntamente à população de adolescentes em conflito com a lei, levando em conta o contexto sociocultural que tais adolescentes estão inseridos. Além disso, almeja-se que os dados encontrados possam estimular reflexões sobre a promoção de práticas interventivas e preventivas aos adolescentes, de modo a minimizar a entrada deste no mundo das drogas e do crime.

\section{Referências}

Almeida, A. M. O. (2009). Abordagem societal das Representações sociais. Sociedade e Estado, 24(3), 713-737.

Almeida, A. M. O., Santos, M. F. S., \& Trindade, Z. A. (2011). Teoria das representações sociais: 50 anos. Brasília, DF: Technopolitik.

Alves, R. F. (2001). O olhar de agricultores do Cariri Paraibano sobre a loucura (Dissertação de mestrado). Universidade Estadual da Paraíba, PB, Brasil.

Assis, S. G.; Constantino, P. (2005). Perspectivas de prevenção da infração juvenil masculina. Ciência e Saúde Coletiva, 10(1), 81-90. https://doi.org/10.1590/S1413-81232005000100014

Assis, S., \& Souza, E. (1999). Criando Caim e Abel: Pensando a prevenção da infração juvenil. Ciência \& Saúde Coletiva, 4(1):131-144. https://doi.org/10.1590/S1413-81231999000100011

Bardin, L. (2010). Análise de conteúdo. Lisboa: Edições 70.

Bastos, A. D. (2002). De infrator a delinquente: O Biográfico em ação (Dissertação de mestrado). Universidade Federal Fluminense, Rio de Janeiro, RJ, Brasil.

Bazon, M. R., Silva, J. L. \& Ferrari, R. M. (2013). Trajetórias escolares de adolescentes em conflito com a lei. Educação em Revista, 29(2), 175-199. https://doi.org/10.1590/S0102-46982013000200008

Bulcão, I. (2001). Investigando as Práticas do Juizado de Menores de 1927 a 1979 (Dissertação de Mestrado). Universidade Federal Fluminense, Rio de Janeiro, RJ, Brasil.

Castro, A. L. S. (2002). Os adolescentes em conflito com a lei. In: S. Koller, Adolescentes e psicologia: concepção, práticas e reflexões críticas (pp.122-128). Rio de Janeiro, RJ: Conselho Federal de Psicologia.

Coimbra, C. M. B., \& Nascimento, M. L. (2005). Ser jovem, ser pobre é ser perigoso? In: JOVENes, Revista de Estudios sobre Juventud, 9(22), 338-355.

Conselho Federal de Psicologia - CFP. (2010). Referências técnicas para atuação de psicólogos no âmbito das medidas socioeducativas em unidades de internação. Brasília, DF: Conselho Federal de Psicologia.

Conselho Nacional de Justiça - CNJ. (2012). Panorama nacional: A execução das medidas socioeducativas de internação. Brasília, DF: CNJ, 2012.

Costa, A. P. M. (2005). As garantias processuais e o direito penal juvenil: Como limite na aplicação da medida sócio-educativa de internação. Porto Alegre, SP: Livraria do Advogado.

Costa, L. S., Carvalho, M. C. N., \&Wentzel, T. R. (2009). Intervenção psicológica focal em adolescentes autores de ato infracional. Ciências \& Cognição, 14(2), 130-146.

Coutinho, M. P. L., Serafim C. N. S., \& Araújo, L. S. (2011). A aplicabilidade do Desenho-estória com tema no campo da pesquisa. In: M. P. L. Coutinho, \& E. R. A. Saraiva (Orgs.), Métodos de pesquisa em Psicologia Social: Perspectivas qualitativas e quantitativas (pp.205-250). João Pessoa, PB: Editora Universitária UFPB.

Cruz, L., Hillesheim, B., \& Guareschi, N. M. F. (2005). Infância e políticas públicas: Um olhar sobre as práticas Psi. Psicologia \& Sociedade, 17(3), 42-49. https:// doi.org/10.1590/S0102-71822005000300006

Espíndula, D. H. P., \& Santos, M. F. S. (2004). Representações sobre a Adolescência a partir da ótica dos educadores sociais de adolescentes em conflito com a lei. Psicologia em Estudo, 9(3), 357-367. https://doi.org/10.1590/S1413-73722004000300004

Lei No 8.609, de 13 de julho de 1990. (1990, 27 setembro). Dispõe sobre o Estatuto da Criança e do Adolescente e dá outras providências. Diário Oficial da União.

Fonseca, A. C. (2013). Consumo de drogas e comportamentos antissociais na adolescência: Que relação. Revista Portuguesa de Pedagogia, 47(1), 157-176. 
Fontanella, B. J. B., Ricas, J., \& Turato, E. R. (2008). Amostragem por saturação em pesquisas em saúde: Contribuições teóricas. Cadernos de Saúde Pública, 24(1), 17-27. https://doi.org/10.1590/S0102-311X2008000100003

Francischini, R. \& Campos, H. R. (2005). Adolescente em conflito com a lei e medidas socioeducativas: Limites e (im)possibilidades. Psico, 36(3), 267-273.

Galduróz, J. C., Noto, A. R., \& Carlini, E. A. (1997). IV Levantamento sobre o uso de drogas entre estudantes do $1^{\circ}$ e do $2^{\circ}$ graus em 10 capitais brasileiras. São Paulo, SP: CEBRID

Jodelet, D. (2001). Representações sociais: Um domínio em expansão. In: D. Jodelet (Org.), As representações sociais (pp.17-41). Rio de Janeiro, RJ: Eduerj.

Lei No 8.609, de 13 de julho de 1990. (1990, 27 setembro). Dispõe sobre o Estatuto da Criança e do Adolescente e dá outras providências. Diário Oficial da União.

Luz, I. F., Eduardo, L. F. L., Mota, N. B. M. \& Pinheiro, A. A. A. (2005). Adolescentes em conflito com a lei: Estudo das práticas efetivadas pela liberdade assistida. Revista de Humanidades, 20(1), 78-85. https://doi.org/10.5020/2318 0714.2005.20.1.\%25p

Maciel, S., \& Roque, L. (2016). Desafios e cuidados na clínica da toxicomania. In: S. Maciel (Org.), Redes de assistência em saúde mental e dependência química: reflexões sobre o cuidado. João Pessoa, PB: Ideia.

Martins, M., \& Pillon, S. (2008). A relação entre a iniciação do uso de drogas e o primeiro ato infracional entre os adolescentes em conflito com a lei. Cadernos de Saúde Pública, 24(5), 1112-1120. https:// doi.org/10.1590/S0102$311 X 2008000500018$

Martins, F., Santo, L. E., Percílio, D., \& Kern, M. C. (2006). Representação social da droga em Brasília: o momento sócio-cultural. Boletim Academia Paulista de Psicologia, 26(1), 42-56.

Melo, J. R. F. (2013). Representações Sociais de dependentes químicos acerca do crack, do usuário de drogas e do tratamento (Dissertação de Mestrado). Universidade Federal da Paraíba, João Pessoa, PB, Brasil.

Minayo, M. C. S.; Sanches, O. (1993). Quantitativo-qualitativo: oposição ou complementaridade? Caderno de Saúde Pública, 9(3), 239-262, https://doi.org/10.1590/S0102-311X1993000300002

Moscovici, S. (1978). A representação social da psicanálise. Rio de Janeiro, RJ: Zahar.

Moscovici, S. (2012). Psicanálise: Sua imagem e seu público. Petrópolis, RJ:Vozes.

Moscovici, S. (2003). Representações sociais. Petrópolis, RJ: Vozes.

Moscovici, S. (2011). Representações sociais: Investigações em Psicologia social (7a ed.). Petrópolis, RJ: Vozes.

Nonticuri, A. R. (2010). As vivências de adolescentes e jovens com o crack e suas relações com as políticas sociais protetoras neste contexto (Dissertação de mestrado). Universidade Católica de Pelotas, Pelotas, RS, Brasil.

Olievenstein, C. (1985). Destino do toxicômano. São Paulo, SP: Almed.

Pereira, S. E. F. N., Sudbrack, M. F. O. (2008). Drogadição e atos infracionais na voz do adolescente em conflito com a lei. Psicologia: Teoria e Pesquisa, 24(2), 151-159. https://doi.org/10.1590/S0102-37722008000200004

Perez, J. R. R., \& Passone, E. F. (2010). Políticas sociais de atendimento às crianças e aos adolescentes no Brasil. Cadernos de Pesquisa, 40(1), 649-673. https://doi.org/10.1590/S0100-15742010000200017

Reis, S. L. A., \& Bellini, M. (2011). Representações sociais: Teoria, procedimentos metodológicos e educação ambiental. Acta Scientiarum Humanand Social Sciences, 33(2), 149-159.

Sá, C. P. (1998). A construção do objeto de pesquisa em representações sociais. Rio de Janeiro, RJ: EDUERJ.

Souza, C. C. S. \& Resende, A. C. (2016). Perfis de personalidade de adolescentes que cometeram homicídio. Psico-USF, 21(1), 73-86. https://doi.org/10.1590/1413-82712016210107

Vala, J. (1993). Representações sociais para uma psicologia social do pensamento social In: J. Vala, \& M. B. Monteiro, Psicologia social (pp. 353-384). Lisboa: Fundação Calouste Gulbenkian.

White, H. R., Jackson, K. M., \& Loeber, R. (2009). developmental sequences and comorbidity of substance use and violence. In: M. D. Krohn, A. J. Lizotte, \& G. P. Hall (Eds.). Handbook on crime and deviance (p. 433- 468). New York: Springer.

Zhang, D., Willson, V., Katsiyannis, A., Barrett, D., Ju, S., Wu, J. (2010). Truancy offenders in the juvenile justice system: a multicohort study. Behavior al Disorders, 35(3), 229-242. 


\section{Samkya Fernandes de Oliveira Andrade}

Mestre em Psicologia Social pela Universidade Federal da Paraíba (2015). Psicóloga pela Universidade Estadual da Paraíba (UEPB), com ênfase em Clínica Logoterapia. Professora no curso de Psicologia na Faculdade Maurício de Nassau. Líder do grupo de Pesquisa e Extensão em Psicologia Social e Saúde na mesma instituição.

E-mail: samkyafernandes@hotmail.com

\section{Railda Sabino Fernandes Alves}

Possui graduação em Formação de Psicólogo pela Fundação Universidade Regional do Nordeste (1982), graduação em Licenciatura Plena Em Psicologia pela Fundação Universidade Regional do Nordeste (1981), mestrado em Evolución Humana, Bases de la Antropología Física, Facultad de Medicina, Universidad de Granada (2006). Mestrado em Saúde Coletiva pela Universidade Estadual da Paraíba (2001) e doutorado em Evolución Humana, Bases de la Antropología Física, Universidad de Granada (2008). Professora doutora C da Universidade Estadual da Paraíba.

E-mail: railda@uepb.edu.br

\section{Maíne Helen Pereira de Almeida Bassani}

Graduanda em Psicologia na Universidade Federal da Paraíba e integrante do Grupo de Pesquisa em Saúde Mental e Dependência Química, coordenado pela Professora Dra. Silvana Carneiro Maciel.

E-mail: mainebassani@gmail.com

Endereço para envio de correspondência:

Departamento de Psicologia.

Rua Baraúnas, 351- Universitário, CEP: 58429-500.

Campina Grande - PB. Brasil.

Recebido 06/05/2017

Reformulado $11 / 12 / 2017$

Aprovado 16/02/2018

Received 05/06/2017

Reformulated $12 / 11 / 2017$

Approved 02/16/2018

Recibido 06/05/2017

Reformulado 11/12/2017

Aceptado 16/02/2018

Como citar: Andrade, S. F. O., Alves R. S. F., \& Bassani, M. H. P. A. (2018). Representações sociais sobre as drogas: Um estudo com adolescentes em conflito com a lei. Psicologia: Ciência e Profissão, 38(3), 437-449. https://doi.org/10.1590/1982-37030000742017

How to cite: Andrade, S. F. O., Alves R. S. F., \& Bassani, M. H. P. A. (2018). Social representations on drugs: A study with adolescents in conflict with the law. Psicologia: Ciência e Profissão, 38(3), 437-449. https://doi.org/10.1590/1982-37030000742017

Cómo citar: Andrade, S. F. O., Alves R. S. F., \& Bassani, M. H. P. A. (2018). Representaciones sociales sobre las drogas: Un estudio con adolescentes en conflicto con la ley. Psicologia: Ciência e Profissão, 38(3), 437-449. https://doi.org/10.1590/1982-37030000742017 